\title{
Clinical Profile, Radiological Resolution and Risk Factors Associated with Community Acquired Pneumonia: Correspondence
}

\author{
Chaudhary $\mathbf{N}^{1}$, Shrestha $\mathbf{S}^{2}$
}

\section{Dear editor,}

W read with interest the article "Clinical Profile, Radiological Resolution and Risk Factors Associated with Community Acquired Pneumonia" in the recent issue of your esteemed journal and found it very useful and informative ${ }^{1}$. This article presents the clinical profile, radiological resolution and risk factors of community acquired pneumonia in children. However, there are certain points we would like to comment and highlight which might bring more clarity to this issue and will be useful to the readers of JNPS.

1. The authors state that all children from two month to 16 years with clinically diagnosed and radiologically confirmed cases of pneumonia were included in this study. The accurate diagnosis of pneumonia in children remains an important yet difficult clinical problem and chest radiograph remains the diagnostic test of choice in tertiary care centres ${ }^{2,3}$. The diagnosis of clinical pneumonia in developing countries is mainly based on the WHO recommendation with the presence of cough, fast breathing and chest indrawing ${ }^{4}$. The authors have not mentioned which diagnostic criteria they have considered in this study to diagnose clinical pneumonia. Again, using the WHO criteria may overestimate the diagnosis of actual pneumonia while the specificity of diagnosing pneumonia using WHO criteria is low $^{5}$. It would have been more informative to the readers, if the authors had provided measures taken to exclude pneumonia like illnesses (like bronchiolitis, asthma and cardiac diseases). In the methodology section, whether only clinical pneumonia or clinical pneumonia along with radiological pneumonia were included in the study needs further clarification. Further, elaboration on criteria for the diagnosis of clinical and radiological pneumonia along with exclusion of other pneumonia like conditions would benefit the readers.

2. Regarding the diagnosis done by chest x-ray, the authors have not mentioned how was radiological pneumonia confirmed (either by the treating paediatrician or a radiologist). In radiological diagnosis, both intra-observer and inter-observer variabilities have ranged from 20 to $25 \%{ }^{6}$. Therefore, it is suggested that $\mathrm{x}$-ray should be read by a paediatrician/radiologist who is blinded with the clinical features of pneumonia. If the above criteria is not fulfilled, there are high chances of observer bias. The readers would be keen to know regarding the radiological diagnosis of pneumonia in this study.
${ }^{1}$ Dr. Nagendra Chaudhary, MBBS. MD. Associate Professor. 'Dr. Sandeep Shrestha' MBBS. MD, Lecturer. Both from the Department of Paediatrics, Universal College of Medical Sciences, Bhairahawa, Nepal.

\section{Address for correspondence \\ Dr. Nagendra Chaudhary \\ E-mail: enagendra@hotmail.com}

\section{How to cite}

Chaudhary N, Shrestha S. Clinical Profile, Radiological Resolution and Risk Factors Associated with Community Acquired Pneumonia: Correspondence. J Nepal Paediatr Soc 2018;38(2):146-147.

doi: http://dx.doi.org/10.3126/jnps.v38i2.21755

This work is licensed under a Creative Commons Attribution 3.0 License. 
3. According to $\mathrm{WHO}$, fast breathing and retraction are important criteria to diagnose pneumonia. Presence of retraction has a specificity of about $98 \%$ in diagnosing pneumonia ${ }^{7}$. The readers would be keen to know what proportion of pneumonia cases had fast breathing and retraction.

4. Downes score is used as a clinical diagnostic means for assessing hypoxemia in clinical respiratory distressed neonates ${ }^{8}$. Downes scoring system should be strictly used for assessing respiratory distress in term neonates. The authors have studied pneumonia in children aged 2 months to 16 years and used Downes scoring system which needs justification of its use in older children.

5. In table 2, authors have mentioned that headache was present in two children who were $<1$ year of age. It is surprising how the authors asked those children who have just learnt to speak bi-syllables (dada, mama) by 12 months.

6. Haemophilus influenza type-b $(\mathrm{HiB})$ and pneumococcal (PCV) vaccines have been introduced in the national immunization schedule of Nepal. It has been seen that the introduction of these vaccines have significantly reduced the radiologically confirmed pneumonia9,10. The vaccination status of all the children enrolled would definitely provide important information to the readers regarding the radiological resolution of pneumonia in the present study.

\section{References}

1. Singh DS, Shrestha NC, Joshi A. Clinical Profile, Radiological Resolution and Risk Factors Associated with Community Acquired Pneumonia. J Nepal PaediatrSoc 2018; 38(1):8-13

2. Lynch T, Platt R, Gouin S, Larson C, Patenaude Y. Can we predict which children with clinically suspected pneumonia will have the presence of focal infiltrates on chest radiographs? Pediatrics 2004; 113(3):e186-9.

3. Cherian T, Mulholland EK, Carlin JB, et al. Standardized interpretation of paediatric chest radiographs for the diagnosis of pneumonia in epidemiological studies. Bull WHO2005; 83:353-59.

4. Programme for the Control of Acute Respiratory Infections, WHO. Technical bases for the WHO recommendations on the management of pneumonia in children at first-level health facilities. Geneva, 1991. http://whqlibdoc.who.int/hq/1991/WHO_ARI_91.20.pdf (accessed Nov 20, 2018).

5. Hazir T, Nisar YB, Abbasi S, et al. Comparison of oral amoxicillin with placebo for the treatment of world health organization-defined non severe pneumonia

\section{Response from Author}

1. The diagnosis of clinical pneumonia in developing countries is mainly based on the WHO recommendation which we also used to diagnose clinical pneumonia, however including the WHO criteria alone would lead to over overestimation and diagnosis of Pneumonia. So we only included those clinical pneumonia that was proved by radiological assessment in this study. Pneumonia like illness was excluded by careful history and by chest x-ray.

2. X-ray should were read by radiologists who were blinded with the clinical features of pneumonia.

3. Even though the respiratory rate and retraction were not mention it on table, we recorded the retraction and RR in each cases for Downes Score only.

4. In assessing the respiratory distress in children, apart from the WHO criteria we had also taken reference of the Downes score for evaluation of respiratory distress in paediatric population. Even though this is not the standard, we had to use some practical method to assess the improvement everyday and before discharge. It has not been mentioned in result or discussion section.

5. We agree to the mistake done in the Perform which showed headache in two infants of 11 and 12 month age.

in children aged 2-59 months: a multicenter, doubleblind, randomized, placebo-controlled trial in Pakistan. Clin Infect Dis2011; 52:293-300.

6. Stickler GB, Hoffman AD, Taylor WF. Problems in the clinical and roentgenographic diagnosis of pneumonia in young children. Clin Pediatr (Phila) 1984;7:398-9.

7. Crain EF, Bulas D, Bijur PE, Goldman HS. Is a chest radiograph necessary in the evaluation of every febrile infant less than 8 weeks of age? Pediatrics 1991; 88(4):821-4.

8. Rusmawati A, Haksari EL, Naning R. Downes score as a clinical assessment for hypoxemia in neonates with respiratory distress. Paediatrica Indonesiana 2008;48(6):342-5.

9. Mulholland $\mathrm{K}$, Hilton $\mathrm{S}$, Adegbola $\mathrm{R}$, Usen $\mathrm{S}$, Oparaugo A, et al. Randomised trial of Haemophilus influenzaetype-b tetanus protein conjugate vaccine for prevention of pneumonia and meningitis in Gambian infants. Lancet 1997; 349:1191-197.

10. Scott JAG, English M. What are the implications for childhood pneumonia of successfully introducing $\mathrm{Hib}$ and pneumococcal vaccines in developing countries? PLoS Med 2008;5(4):e86. 